
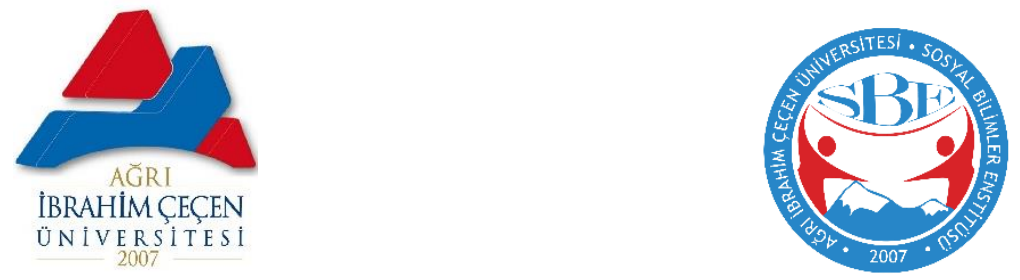

BAYBURT MAHALLE ODALARININ FOLKLORIK AÇIDAN INCELENMESI

The Importance Of Bayburt District Rooms in Terms Of Folklore

Arş. Gör. Özlem ÜNALAN

Bayburt Üniversitesi İnsan ve Toplum Bilimleri Fakültesi, Türk Dili ve Edebiyatı ozlemunalan@bayburt.edu.tr

https://orcid.org/0000-0001-5345-6499

Ağrı ibrahim Çeçen Üniversitesi Sosyal Bilimler Enstitüsü DergisiJournal of Ağrı ibrahim Çeçen University Social Sciences InstituteAiCUSBED 7/1 Nisan/April 2021 / Ağrı

ISSN: 2149-3006

e-ISSN: $2149-4053$

\begin{tabular}{|l|l|}
\hline Makale Türü-Article Types : & Araştırma Makalesi \\
\hline Geliş Tarihi-Received Date : & 09.02 .2021 \\
\hline Kabul Tarihi-Accepted Date : & $\mathbf{0 5 . 0 3 . 2 0 2 1}$ \\
\hline Sayfa-Pages : 221-232 & doi https://doi.org/10.31463/aicusbed.877234 \\
\hline
\end{tabular}

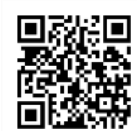

http://dergipark.gov.tr/aicusbed

This article was checked by

$\checkmark$ iThenticate 



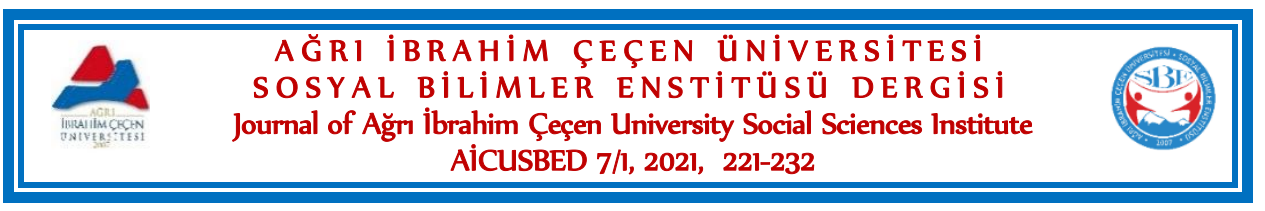

\title{
BAYBURT MAHALLE ODALARININ FOLKLORİK AÇIDAN İNCELENMESİ*
}

The importance of Bayburt District Rooms in Terms of Folklore

\author{
Arş. Gör. Özlem ÜNALAN
}

\begin{abstract}
$\ddot{O} z$
Bayburt gelenek ve göreneklerini günümüzde de devam ettiren kadim şehirlerden biridir. Türkiye'de sadece Bayburt'a özgü olan mahalle odaları halkın toplanıp bir araya geldiği sevincini ve üzüntüsünü paylaştığı eğlenip hoşça vakit geçirdiği sosyal bir mekândır. Kız isteme, cenaze, düğün-kına, bayramlaşma, herfene vb. birçok tören ve uygulama için mahalle sakinleri mahalle odalarında toplanır. Belediye başkanı, vali, rektör, kaymakam, emniyet müdürü gibi bazı bürokratlar mahalle odalarında halk ile buluşur, halkın sorunlarını dinler, onlarla bayramlaşır. Burada yemekler yenir, şiirler söylenir, âşı fasılları düzenlenir, yöresel oyunlar oynanır, önemli konuşmalar yapılıp önemli kararlar alınır.

Bayburt mahalle odaları geçmişten günümüze birçok amaca hizmet eder ve bu bağlamda birçok insanı bir araya getirir. Gelenek ve göreneklerin, sözlü kültür ürünlerinin korunması ve gelecek nesillere aktarılmasında önemli bir yer ihtiva eder. $\mathrm{Bu}$ sebepten Bayburt mahalle odalarını birer kültür abidesi olarak görmek ve kültür taşıyıcısı olarak nitelendirmek yanlış olmaz. Diğer taraftan mahalle odaları toplumsal kaynaşmayı sağlar, kişiye toplum olma bilinci ve aitlik duygusu kazandırır. $\mathrm{Bu}$ bağlamda benden ziyade biz olmanın, toplumsal birliktelik ve dayanışmanın güzel bir örneğini sergiler.

Bu çalışmada Bayburt mahalle odalarının bir nevi tanıtımı yapılacak, folklorik açıdan önemi ortaya konulacaktır. Mahalle odalarının işlevleri kaynak kişilerden yapılacak derlemeler ışığında ele alınacaktır.
\end{abstract}

Anahtar Kelimeler: Köy Odaları, Bayburt, Halk Kültürü, Gelenek

\section{Abstract}

Bayburt is one of the ancient cities that continues its traditions and customs today. District Rooms which are specific to only Bayburt in Turkey are social places where people come together where they share their happiness and sadness, where they enjoy happily. District people come together in district rooms for many celebrations and practices such as for marriage asking, funeral, wedding-henna, celebrating Bairam, common diner etc.

Some bureaucrats like mayor, governor, rectors, caimacam, and police chief meet with people in district rooms, listen the problems of people, and celebrate their Bairam. People have their meals here, they read poems, they organize minstrel

\footnotetext{
* Bu makale 12-14 Mayıs 2017 tarihleri arasında düzenlenen Uluslararası Türk Dili ve Edebiyatı Bilgi Şöleni'nde bildiri olarak sunulmuştur.
} 
ceremonies, they dance regional dances, and they speak about important topics and decide about important things.

Bayburt district rooms serve lots of purposes from history to now and from this perspective they calls people together. Tradition and customs are important to protect oral culture products and transfer them to future generations. For this reason, it is not wrong to see Bayburt district rooms as culture memorial and culture carrier. On the other hand, district rooms provided social solidarity and bring a person conscious of being a society and belonging. From this context, they exhibits being "us" more than "I", it also exhibits social cohesion and a good example of solidarity.

In this study, Bayburt District rooms will be presented somehow; its importance in terms of folklore will be presented. The functions of district rooms will be covered under the light of compilations from source people.

Keywords: Village Rooms, Bayburt, Folk Culture, Tradition.

\section{Giriş}

Türk kültüründe yardımlaşma, dayanışma, misafirperverlik önemli bir husustur. Bu doğrultuda Anadolu'nun birçok yerinde, çok sayıda köy odası hizmet vermektedir fakat şehir merkezlerinde köy odalarının yerini tutacak bir yap1 mevcut değildir. Çay bahçeleri, mesire alanları, cafeler, restoranlar her ne kadar halkın toplanıp yiyip içtiği sosyal mekânlar olsa da kültürel manada bu mekânlar yetersiz kalmaktadır.

Bayburt'taki köylerde köy odası geleneği devam etmekle birlikte merkezde mahalle odaları bulunmaktadır. $\mathrm{Bu}$ yönü ile Bayburt diğer şehirlerden ayrılmaktadır. Köy odalarının pek çok işlevini mahalle odaları karşılamakla birlikte bunları birbirinden ayıran bazı hususlar da vardır.

Köy odaları genellikle giriş ve salon olmak üzere iki bölümden oluşur. Mahalle odalarında ise bu odalara ilaveten mutfak, misafirhane, yönetici odası gibi müstakil ayrı odalar da yer almaktadır. Ayrıca köy odaları her gün, sabah akşam açık tutulurken mahalle odaları taziye günleri ve kahve merasimleri gibi özel günler hariç genellikle kapatılmaktadır (Şengün ve Dursunoğlu, 2020: 18).

Geçmişten günümüze bir gelenek olarak devam eden mahalle odası anlayışı, Bayburt'un kültürel değerlerinin yaşatılması ve korunmasına büyük hizmet eder. Mahalle odaları yalnızca kadın veya erkeklerin oturup sohbet ettikleri bir mekân değil aynı zamanda birer kültür merkezidir.

Müstakil mahalle odaları kurulmadan önce Bayburt'taki ünlü konaklar ve zengin kimselerin büyük evlerindeki bir ya da birkaç oda, mahalle halkının bir araya geldiği mekânlar olmuştur. Zamanla bu mekânlar ihtiyacı karşılayamamış bu da müstakil konakların inşa edilmesini gerektirmiştir. Müstakil yapılan mahalle odalarının inşası odaların işlevlerinden hiçbir şey

http://dergipark.gov.tr/aicusbed 7/1 Nisan/April 2021 
kaybettirmemiş aksine işlevini, değerini ve gereksinimi artırmıştır (Aker tarihsiz: 67).

Büyük şehirlerin her geçen gün yalnızlaşmaya ve yabancılaşmaya başlayan insan profilleri karşısında Bayburt mahalle odaları bireye birlik ve beraberliği, yardımlaşmayı ve paylaşmayı öğretir. Bayburt'un kültürel zenginliğini gün yüzüne çıkarır ve unutulmaya yüz tutmuş değerlerini hatırlatır.

Mahalle odalarının belli bir oturma düzeni vardır. Başköşeye oturacak kişi orada bulunan grubun çeşidine ve statüsüne göre değişir. Örneğin belediye başkanı, vekil, bakan gibi üst kademeden kişiler başköşeye oturur. Bunun dışında başa en yaşl, en bilgili veya âlim görülen kişi, onun sağı ve soluna da diğer kişiler oturur (Kaynak Kişi 1).

$\mathrm{Bu}$ odaların kapısı herkese açıktır. Kadından erkeğe, gencinden yaşlısına, zengininden fakirine herkes bu odalardan istifade eder. Kimi zaman Bayburt'un sorunları burada tartış1ır, çözümler üretilmeye çalışılır. Kimi zamansa mahalle odaları halk ile aydın kesimin buluşup kaynaştığı mekânlar halini alır. Mahalle odaları bu bağlamda kaymakam, vali, emniyet müdürü, komutan, rektör, milletvekili, bakan, savcı, hâkim gibi önemli kişilere de ev sahipliği yapar (Kaynak Kişi 2).

Mahalle odaları mahallelinin ortak malıdır. Burasının tüm ihtiyacı mahalle sakinlerinin verdikleri paralarla karşılanır. Para toplama ve ihtiyaçları karşılama işi dernek tarafından yürütülür. Her mahalle odasının kendi adını taşıyan bir derneği bulunur. Dernek yönetimi mahallede evi bulunan mahalle sakinlerini derneğe kaydeder. Genelde evin en büyüğü kimse o derneğe üye yapılır. Erkek çocuklar evlenip evden ayrıldığında ise bu kişiler ayrıca üye olarak kaydedilir.

Mahalle odalarının ihtiyaçları mahalle sakinlerinden yıllık olarak toplanan çok cüzi paralarla giderilir. Bunun dışında mahalle halkının veya hayırseverlerin bağışları ile odalar faaliyetlerini sürdürür (Kaynak Kişi 3).

\section{Mahalle Odalarının Tarihçesi}

Bayburt mahallelerinin bilinen tarihi geçmişi 16 . yüzyıla dayanır. Öncesinde kurulan mahalle isimleri Selçuklu ve beylikler dönemine ait kaynaklarda tespit edilememiştir. Mehmet Ağa komutasındaki Osmanlı askerlerinin 1514'te Bayburt Kalesi'ni ele geçirmesinden sonra ilk mahalleler kurulur. O dönemlerde tarıma uygun araziler yerleşime yasaklandığı için evler kalenin yamaçlarına yapılır ve böylece ilk mahalleler kalenin çevresinde oluşturulur. Şingah (Mehmet Çelebi), Bent (Kadızade), Kaya (Uzungazi), 
Karasakal, Veysel Efendi ve Zahit Mahalleleri ilk kurulan mahallelerdir. Sonraki dönemlerde ise Kaleard 1 ve Galer (Tuzcuzade) Mahalleleri kurulmuştur (Sülo 2002: 91-92).

Bayburt'ta kurulan bu mahalle adlarını Bayburt'un Osmanlı yönetimine geçmesi ile hazırlanan tapu tahrir defterlerinden, temettuat defterlerinden ve Evliya Çelebi seyahatnamesinden öğrenmekteyiz. Bayburt'ta ilk tahrir çalışması 1516 yılında yapılmıştır. Sonrasında yapılan tahrir çalışmaları Bayburt'un XVI. yüzyılda on mahallesinin bulunduğunu ortaya çıkarmıştır (Özger 2008: 178).

Evliya Çelebi 1647'de Bayburt'a geldiğinde Bayburt Kalesi hakkında da bilgi vermiş kaleyi büyük ve ihtişamlı bulmuştur. Kale içerisinde üç yüz civarında eski usul, kalenin dışındaki şehirde ise toprak üstlü bin kadar ev bulunduğunu belirtmiştir. Ayrıca şehrin on dokuzu Müslüman yedisi Ermeni olmak üzere yirmi altı mahalleden oluştuğunu söylemiştir. Yurt Mahallesi dışında başka mahalle ismine yer vermemiştir (Evliya Çelebi Seyahatnamesi 1993: 174).

Günümüzde Bayburt merkeze bağlı on dört mahalleden oluşur. Bunlar: Camikebir, Esentepe, Gençosman, Halfikale (Kaleardı), Kadızade, Karasakal, Mehmet Çelebi, Şeyhheyran, Şingah, Tuzcuzade, Uzungazi, Velişaban, Veysel, Zahit Mahalleleridir (URL-1).

Bayburt'ta mahallelerin kurulmaya başlanmasıyla birlikte mahalle halkının bir araya gelip istişare edebileceği mekânlar ortaya çıkmıştır. Önceleri bu mekânlar Bayburt'un ileri gelen nüfuzlu kişilerinin konakları olmuştur. Bu tür konakların en büyük odası halkın toplanma yeri bilinmiş mahallenin ve şahısların sorunları buralarda dinlenmiş bayramlarda yemekler verilmiş ve halk bu konaklarda bayramlaşmıştır. Her mahallede o mahalleye mensup olan ve hanedan olarak görülen mahalle sakinlerine ait odalar 1980'li yılların başına kadar faaliyetlerini sürdürmüştür (Sülo 2002: 92).

Zamanla bu konaklar yetersiz gelmiş ve mahalle halkının ihtiyaçları doğrultusunda mahalle odaları açılmaya başlanmıştır. İlk mahalle odası 1970'li yıllarda Tuzcuzade Mahallesi'nde açılmıştır. Ağırlama sofası, yemekhanesi, gasilhanesi ve kenefiyle birlikte sistemli biçimde kurulan ilk mahalle odası 1981'de faaliyete geçen Şingah mahalle odasıdır (Kaynak Kişi 4).

Şingah mahalle odasının kurulma fikri "Mevlüt kandili için toplanan paraların artanı ile ne yapılabilir?" Düşüncesinden ortaya çıkmıştır. Mahallenin ileri gelenleri artan bu parayla cami yanına taziye yeri ve akşamları görüşüp konuşmak için ahşaptan küçük bir yer yaptırmayı isterler.

http://dergipark.gov.tr/aicusbed 7/1 Nisan/April 2021 
O dönemin muhtarının, Şingah Mahallesi Yardımlaşma ve Dayanışma Derneği Başkanı'nın ve Hanefi Ağın, Baha Erbay, Hacı Dursun Yerlikaya gibi mahalle büyüklerinin de onayı alınınca 1979'da mahalle odasının yapımına başlanır. Şingah mahalle odasının yapım aşamasında halk büyük bir özveri göstermiş genç yaşlı herkes çalışmış kadınlar dokuyup ev geçimine katkıda bulundukları ehramlarını bağışlamışlardır. Diğer taraftan cuma namazında toplanan paralar ve başka şehirlerde ikamet eden Bayburtluların bağışları ile 1981 'de Şingah mahalle odası tamamlanmıştır. İnşaatın ilk görüntüleri bir arı kovanını andırdı ̆̆ı için önce beğenilmemiş fakat yapılıp bittikten sonra mimarisi ile herkesi büyülemiştir. Ayrıca oda cami yanında yapıldığı için de eleştirenler olmuştur. Odada düzenlenen ilk cenaze merasiminin odanın yapımına en çok karşı çıkan kişiye nasip olması da efsane olarak anlatılmaktadir. (URL-2)

Günümüzde Bayburt merkezinde on dört mahalle bulunmakta ve neredeyse her mahallede birer mahalle odası yer almaktadır (Şengün ve Dursunoğlu, 2020: 9-10).

Şingah ve Genç Osman Mahallesi’nde olduğu gibi bazı mahallelerin odası birden fazladır. Mahalle odası olmayan mahalle halkı da komşu mahallenin odasını kullanır.

Halkın ihtiyaçlarını karşılamak ve bu geleneği yaşatmak için Bayburt'ta site biçiminde yapılan bazı binaların altına mahalle odaları yapılır veya alt kattaki boş bir daire mahalle odası haline getirilir.

\section{Odaların Fiziki Özellikleri}

Bayburt mahalle odaları sıradan yapılmış odalar değildir. Özellikle bazı mahalle odaları son derece ihtişamlı ve güzeldir. Bunlardan Şingah mahalle odasının gerek büyüklüğü gerekse mimari özellikleri ile ayrı bir önemi vardır. Odanın mimari yapısı arıların petek yapışından esinlenerek düz bir zemin ve altıgen şema üzerine kurulmuştur. İki katlı olup alt katta gasilhane ve kenef, üst katta ağırlama sofası ve yemekhanesi bulunur. Aynı anda birkaç faaliyeti gerçekleştirmek için her bir odanın girişi dış kapıya açılacak biçimde inşa edilmiştir. Diğer taraftan yaşlı ve gençlerin aynı bölümde fakat ayrı bir biçimde konuşlanabilmesi için ağırlama sofası iki yönlü yapılmıştır. İnşa edildiği dönemde ekonomik kaygılar taşımasına rağmen mükemmel bir mimari ortaya konulmuş ilerleyen yıllarda Şingah mahalle odası daha da zenginleştirilip genişletilmiştir (URL-2).

Mahalle odalarının tümü gelen misafirlerin ihtiyaçlarına göre düzenlenmiş ve onların konforları düşünülmüştür. Mimarisi itibariyle de son 
derece şık ve moderndir. Geleneksel mimari ile modernleşmiş yapının bir sentezini oluşturur.

Mahalle odalarının geniş bir oturma salonu bulunur. Gelen misafirler bu salonda ağırlanır, burada sofralar kurulur, sohbetler yapılır. Misafirlerin oturması için salonda makat olarak isimlendirilen koltuklar yer alır. Bunlar koltuk gibi yerden yüksektir, alt kısmı genellikle ahşaptır ayrıca ahşap sedirin üzerinde minderler yer alır. Bazı sedirlerin üzeri ve sırt kısımları kadife kumaş ile kaplanmıştır. Sofralar genellikle yere serilir ve yerde yenir. Eğer ikramlıklar söz konusu ise misafirlerin önüne sehpalar getirilir, ikramlar bu şekilde sunulur (Kaynak Kişi 3).

Odanın duvarları genellikle sadedir, bazı mahalle odalarının salonlarında ayet içeren veya Bayburt'un çeşitli yerleri üzerine yapılmış tablolar ve saat asılıdır. Özellikle daha önceden inşa edilmiş bazı mahalle odalarının duvarları ve yerleri ahşaptır. Aynı şekilde bazı odaların tavanları beton iken bazı odaların tavanları ahşap ve ters tavan kaplamalıdır. Salon baştanbaşa halı ile kaplıdır. Bir mahalle odasında salonun dişında genel olarak mutfak, çay ocağı, gasil odası (cenaze yıkama odası), kütüphane, yatakhane, idare odası, Kur'an odası yer alır. Özellikle köylerdeki odalarda ısınmak için soba kullanılır ama Bayburt merkezindeki mahalle odaları doğal gaz veya kalorifer ile 1sınmaktadır. Bakım, tamirat veya odanın herhangi bir eksiği söz konusu olduğunda bunlar eksiksiz bir biçimde yapılmaktadır. Eskiden mahalle odalarının aydınlatılması yağdanlıklar, fitilli pompalı lambalar ile yapılırken günümüzde odalar şık avizelerle süslenmiştir (Kaynak Kişi 5).

Bazı mahalle odalarında ölen kişinin adı ve soyadının, ölüm tarihi ve sebebinin verildiği defterler bulunmaktadır. $\mathrm{Bu}$ defterler vasitasıyla o mahallede kimlerin, ne zaman yaşadığı tespit edilir (Kaynak Kişi 5).

Odalara "cümle kapısı adı" verilen dış kapıdan girilir. Girişte genellikle bir koridor bulunur ve bu koridorun ortasında veya baş tarafında abdest almak için ibrikler, havlu ve abdest suyunun akmasını sağlayan ve "kerhiz taşı" adı verilen bir lavabo bulunur (Sülo 2002: 95).

\section{Mahalle Odalarının Folklorik İşlevleri}

Mahalle odaları özellikle uzun kış gecelerinde gençlerin, kadınların ve erkeklerin bir araya geldikleri masallar, hikâyeler anlatıp oyunlar oynadıkları yemekler yiyip çay ve kahve içtikleri sosyal mekânlardır. Bu manada günümüzün modern kafelerini mahalle odalarının bünyesinde bulmak mümkündür. Zira Bayburt nüfus ve yüzölçümü itibariyle Türkiye'nin küçük şehirlerinden biridir. Büyük şehirlerde karşılaştı̆̆ımız devasa alışveriş 
merkezleri ve eğlence mekânları Bayburt'ta yoktur. Bu da özellikle kış günlerinde insanların bir araya gelebilecekleri mekân ihtiyacını doğurmuştur. Diğer taraftan evler, erkeklerin bireysel olarak bir araya gelme arzularından dolayı ve fiziki koşulları itibariyle yeterli olmamıştır. Böylesi durumlarda mahalle odaları, mahalle sakinlerinin bir araya geldikleri sohbet yerleri haline gelmiştir.

Mahalle odaları yalnızca kış gecelerinde değil Ramazan aylarında da Bayburt halkının toplandığı bir mekândır. Mahalle odalarında bazen iftarlar verilir bazen de iftardan sonra erkekler mahalle odasinda bir araya gelir. Burada sahura kadar sohbet edilir, Kur'an okunur, dualar yapılır, sahura yakın herkes odadan ayrilır ve evine döner (Kaynak Kişi 6).

Mahalle odaları sözlü kültür ürünlerinin yaratılması ve yaşatılmasında önemli yer ihtiva eder. Masallar, çocuk oyunları, türküler, âşık şiiri, maniler, hikâyeler, efsaneler, bilmeceler, köy seyirlik oyunları sözlü kültür ürünlerinin birer parçasıdır. Özellikle televizyon, bilgisayar gibi teknolojik aletlerin yeterince gelişmediği yıllarda büyük küçük birçok insan köy ve mahalle odalarında toplanmıştır. En yaşlı veya bilgili görülen kişi hikâyeler, fikralar, efsaneler anlatmış bilgi ve deneyimlerini paylaşmıştır (Kaynak Kişi 3).

Mahalle odaları özellikle bundan otuz, kırk yıl öncesinde adeta bir mektep vazifesi görmüştür. Bayburt'un yetiştirdiği önemli âlimler, mahalle odalarında halkı bir araya toplamış burada sohbetler etmiş başta dinî konular olmak üzere çeşitli konularda halkı bilgilendirmişlerdir. Gençler toplum içinde nasıl oturup kalkacaklarını, büyüklerinin yanında nasıl konuşacaklarını buralardan öğrenmişlerdir (Kaynak Kişi 6).

Mahalle odaları, halk şairleri için de birer meclis vazifesi görmüştür. Çeşitli şehirlerden gelen veya Bayburt'ta yetişen halk şairleri, saz ve sözlerini mahalle odalarında icra etmişlerdir. Âşıklar burada halkın huzurunda atışmalar yapmış deyişler söylemiştir. Bu da âşıklık geleneğinin tanıtılmasını ve geleneğin devamlılığını sağlamıştır. Celâli, Hicranî gibi Bayburt'un yetiştirdiği önemli halk şairleri şiirlerini mahalle odalarında dile getirmiştir. Günümüz âşılarından Bayburtlu Süphanî de mahalle odalarında zaman zaman şiir programları yapmaktadır.

Diğer taraftan mahalle odaları, insanların mutlu anlarını paylaştıkları kutlamalar ve eğlenceler yaptıkları geleneksel bir mekân olma özelliği de taşır. Bu husus özellikle kahve içme merasimi ve sağdıç gecelerinde görülür.

Bayburt'ta evlenme çağına gelmiş erkeklere kız bakmaya gidilir. Kız beğenilirse kız evi birkaç kez ziyaret edilir ve kız ailesinden istenir. Kızın ailesi birkaç gün müsaade aldıktan sonra kızı vermeye karar verirse ve aileler 
arasında gerekli anlaşma sağlanırsa kahve içme günü tespit edilir. Kahve içme merasimi Bayburt'ta alışılagelenden biraz daha farklıdır ve davetiye usulü yapılır. Tıpkı düğün davetiyesi gibi kahve merasimi için de davetiye bastırılır. Eş dost, komşu ve yakınlara davetiye dağıtılır. Davetiyelere kız ve erkek babalarının adları, mahalle odasının adı, tarih ve saati yazılır. Erkek tarafi başka bir mahalleden gelecekse erkek tarafı otobüs tutar ve davet ettiği yakınlarını araçla mahalle odasına götürür (Kaynak Kişi 2). Kahve günü sabahında oğlan tarafi kız tarafına şeker, kolonya, lokum, sigara ve kahve gönderir. Davetiyede yer alan mahalle odasında sadece erkeklerin katılımı ile kahve içme merasimi gerçekleşir. Bazen kahve içme merasimi çok kalabalık olur. Burada erkek tarafı kızın büyüklerinden kızı tekrar ister, kız tarafı da kızlarını verdiklerini söyledikten sonra kahveler içilir. Bazen kahve içme merasiminin ardından gelin ve damadın dinî nikâhları kıyılır ve dualar okunur. Erkek tarafının gönderdiği lokum ve şekerler ikram edilir. Ardından bir tepsinin içerisinde damadın babasına veya ailenin bir büyügüne şerbet veya bir kahve daha gelir. Oğlanın babası veya ailenin büyüğü kahveyi içtikten sonra ikram yapan gençlere verilmek üzere tepsiye bahşiş bırakır. Sohbet ve dualar edildikten sonra misafirler dağılır. Bayburt'ta bu merasime kahve içme veya tatl kahve ad1 verilir (Emir ve Adak 2011: 37).

Günümüzde azalmakla birlikte bazı aileler mahalle odalarında çeyiz serme geleneğini devam ettirmektedir. Evlenecek kızların çeyizi bulundukları mahallenin odasında birkaç gün görücüye çıkarılır. Gelinin arkadaşları, komşu ve akraba kadınlar çeyizi gezmeye gelir. Erkek ve kız tarafından birkaç kişi muhtar eşliğinde gelinin çeyizini yazar. Gelin tarafı bu işlemin ardından muhtar ve diğer kişilere havlu, çorap, gömlek gibi hediyeler verir (Sülo 2002: 96).

Mahalle odaları düğünler için de kullanılır. Dügün evi misafirleri ağırlamada yetersiz kaldığında özellikle uzaktan gelen misafirler mahalle odasında ağırlanır. Misafirler burada yedirilir, içirilir ve yatırılır.

Bayburt'ta kına gecelerine çoğunlukla erkekler katılmaz, kadınlar ise kına gecesini evde veya önceden tutulan salonlarda yaparlar. Her iki tarafin erkekleri de mahalle odalarında toplanırlar. Burada sohbetler edilir, türküler söylenir, barlar oynanır ve ikramlar yapılır.

Aynı zamanda mahalle odaları erkek sağdıç gecelerinin de düzenlendiği mekânlardır. Damadın arkadaşları ve mahalledeki diğer erkekler mahalle odasında toplanırlar. Zaman zaman erkekler kadın kılı̆̆ına girerek taklitler yaparlar. Damat bir yarışmaya tabi tutulur ve damada şakalar yapılır. Sazlı sözlü bir eğlence düzenlenir. Erkekler kendi aralarında kayış kızdı,

http://dergipark.gov.tr/aicusbed 7/1 Nisan/April 2021 
herkes benim gibi olsun, vız-dız, düdük saklama, kabak, kaz çoban oyunu, sayman (turp), dişçi oyunu, hızır, değirmenci, berber, doktor, tilki geldi, kaynana-damat gibi seyirlik oyunlar oynarlar (Gedik 1991: 13). Bu bağlamda mahalle odalarını düğünlerde insanları bir araya getiren birer eğlenme mekânı olarak görmenin yanında geleneksel oyunların oynandığı ve yaşatıldığı birer kültür taşıyıcısı olarak da nitelendirmek mümkündür (Kaynak Kişi 5).

Mahalle sakinlerinden birinin vefat etmesi üzerine merhumun bağlı olduğu mahalle odası muhtar aracılığıyla devreye girer. Mahalle odasına ait dernek öncelikle merhumun şehir içi ve dışındaki yakınlarına haber ulaştıırır. Aile sadece mezarlığı ve kabir yerini belirler, dernek mezarın kazılma işini de üstlenir. Cenaze namazının hangi camide kılınacağı ve merhumun defnedileceği mezarlık belediye anonsu ile duyurulur. Mahalle odasının gasilhane bölümünde caminin imamı merhumu yıkayıp kefenler. Ardından merhum cenaze arabasina konularak mahalle odasinda toplanan cenaze yakınları tarafından mezarlığa götürülür ve defnedilir. Cenazenin defin işlemi ardından cenaze yakınları mahalle odasına dönüp üç gün boyunca taziyeleri kabul ederler. Erkekler mahalle odasında toplanır ve baş sağlığına gelen tüm erkekler de buraya gelir. Kadınlar ise cenaze evine gidip taziyelerini bildirir. Mahalle odasının mutfak bölümünde yemekler hazırlanır ve cenaze yakınlarına ikram edilir. Mahalle odasının dernek üyeleri tarafından veya önceden belirlenmiş bir aşçı tarafından yemekler yapılır. Üç gün mahalle odası merhumun ziyaretçilerine açık kalır ve yemekler sunulur. Hatta burada hazırlanan yemekler kadınların bulunduğu cenaze evine de gönderilir (Kaynak Kişi 3).

Cenaze yakınları, yakınlarını kaybetmenin üzüntüsünü yaşarken yapılması gereken tüm işler mahalle odasının dernek üyeleri ve muhtar tarafindan yapılır. Genellikle cenaze masrafları için cenaze sahibinden ekstra bir para talep edilmez. Tüm masraflar önceden toplanan y1llı aidatlarla karşılanır. Mahalle odaları etrafında oluşan bu gelenek hem psikolojik olarak cenaze yakınlarına bir destek ve yardım sunmakta hem de unutulmaya yüz tutan değerlerimizin yaşatılmasına katkı sağlamaktadır. İnsanlar burada bir araya getirilerek üzüntülerini paylaşır, uzun zamandır birbirini görmeyen insanlar birbirlerini görüp hasret giderir. Cenazenin arkasından mevlitler okunur, dualar edilir.

Diğer taraftan mahalle odaları düğünlerin yanında bayram veya cenaze gibi özel durumlarda şehir dışından gelen misafirlerin ve Bayburtlu gurbetçilerin konakladıkları yerlerdir. Cenaze sakinin evi misafirleri 
kaldıramadığg durumlarda bu kişiler hemen mahalle odasında misafir edilir, orada bulunan yataklarda yatırılır.

Bazı mahalle odalarında mahalleli kadınlar dinî sohbet yapmak ve Kur'an okumak için toplanırlar. Burada Kur'an dersleri verilir. Kadınlar evlerinde hazırladıkları pasta, börek veya yemekleri burada yerler. Bazı mahalle odaları zaman zaman ihram atölyesi olarak da hizmet etmiştir. Söz konusu bu odalarda bir araya gelen kadınlar birbirlerine dantel, dikiş, nakış vs. öğretmektedir (Kaynak Kişi 7). Genç kızlar burada yemekli eğlenceler yapar; yüzük, kabak, dokuztaş, fincan, deli kız gibi geleneksel oyunları oynar (Gedik1991: 19).

Aynı zamanda mahalle odaları geçmişten günümüze Bayburt mutfak kültürünün ve herfene geleneğinin yaşatıldığı yerler olmuştur. Herfene, herkesin kendisine düşen yemeği getirerek müşterek yenilen yemek, ortaklaşa malzeme ile yapılan yemekli eğlencedir. Yazın daha çok piknik yerleri ve mesire alanlarında yapılan herfene kışın daha çok evlerde, mahalle ve köy odalarında yapılmaktadır. Herfeneye tatlı çorba, tarhunlu börek, çekme helva, lor dolmas1, imir dolması, kabak borani, yalancı dolma, ziron gibi yöresel yemekler getirilir (Kaynak Kişi 2).

Günümüzde mahalle odalarında Bayburt Üniversitesi öğrencilerine yönelik herfeneler düzenlenmektedir. Böylece hem Bayburt gelenek ve kültürü öğrencilere tanıtılmakta hem de öğrencilerle fikir alışverişi yapılmaktadır.

Mahalle odaları Ramazan ve Kurban bayramlarında halkın bayramlaştıkları yerlerdir. Her bayram farklı mahalle odasında protokol ile vatandaşlar bayramlaşır. Bu durum Bayburt'ta gelenek hale gelmiştir ve her bayram değişen protokolle halk bir araya gelir. Odaya giren kişi önce selam verir, ardından herkesle tek tek tokalaşır. Halk ile protokol üyelerine bayramlıklar ikram edilir, çay veya kahve içilir ve çocuklara oyuncaklar dağıtılır.

\section{Sonuç}

Mahalle odaları çok sayıda fonksiyonu ile Bayburt kültürünün yaşatılmasında ve gelecek kuşaklara aktarılmasında önemli bir yer edinmiştir. Bugün neredeyse her mahallede varlığını sürdüren mahalle odaları, gündelik hayatta veya özel günlerde halkın bir araya geldiği sosyal bir mekân vazifesi görür. Bayramlaşmalar, taziyeler ve kahve içme merasimi mahalle odalarında gerçekleşir. Halk şairleri şiirlerini mahalle odalarında icra eder, dinî ve edebi 
sohbetler buralarda yapılır. Mahalle odalarında yataktan, mutfak gereçlerine bir topluluğun ihtiyaçlarını karşılayacak neredeyse her şey bulunur. Kendine has bir mimarisi ve dekorasyonu vardır. İnsanların birliktelik ve beraberlik duygusunu artırdığ 1 gibi gelenek ve göreneklerin uygulanmasına da imkân tanır. Mahalle odaları yemeklerle, oynanan geleneksel oyunlarla ve düzenlenen çeşitli etkinliklerle geleneğin uygulanma alanlarıdır.

\section{Kaynaklar}

Aker, A. (t.y). Hicranı Anlayan Şehir. Bayburt: Özer Matbaacılık.

Evliya Çelebi Seyahatnamesi II. (1993). (Haz. Kurşun Zekeriya, Kahraman Seyit Ali, Dağlı Yücel), İstanbul: Yapı Kredi Yayınları.

Gedik, Köksal. (Nisan 1991). "Bayburt ve Çevresinde Oynanan Seyirlik Oyunlar 1". Gazi Bayburt, 16-17.

Gedik, Köksal. (Haziran 1991). "Bayburt ve Çevresinde Oynanan Seyirlik Oyunlar 3". Gazi Bayburt, 13-14.

Emir, Dursun A. ve Adak, M. (2011). Kültürün Kale Kenti Bayburt. Ankara: Bekder Yayınları.

Özger, Y. (2010). XIX. yüzyıl Bayburt (Sosyo-Ekonomik, İdari ve Demografik Yapı). İstanbul: IQ Kültür ve Sanat Yayıncılık.

Sülo, L. "Bayburt Mahalle Odaları". (2002). 17-19 Temmuz 1999 10.Yılında Bayburt Vilâyeti Sempozyumu), Ankara, 2002: 91-96.

Şengün, H. , Dursunoğlu İ. (2020). Kent, Kimlik ve Kültür Ekseninde Bayburt Mahalle Odaları. Ankara: İmaj Yayınevi.

URL-1: https://www.bayburt.bel.tr/muhtarliklar. Erişim tarihi: 07.05.2017

URL-2:https://www.bayburtpostasi.com.tr/kultur-sanat/anadolu-ya-has

kultur-bayburt-a-has-odalarda-yasiyor-h16528.html.Erişim tarihi: 07.05.2017

\section{Sözlü Kaynaklar}

(Bu derleme 2017 yılında yapılmıştır)

Kaynak Kişi 1: Abdulkadir Temur, 65 yaşında, lise mezunu, aktar, Bayburt/Merkez.

Kaynak Kişi 2: Songül Keskin, 82 yaşında, ilkokul mezunu, ev hanımı Bayburt/Merkez.

Kaynak Kişi 3: Ali Fuad Değirmenci, 54 yaşında, üniversite mezunu, esnaf, Bayburt/Merkez.

Kaynak Kişi 4: Fahmettin Kalacoş, 42 yaşında, üniversite mezunu, din görevlisi, Bayburt/Mutlu Köyü. 
Kaynak Kişi 5: Hakan Kurt, 45 yaşında, üniversite mezunu, öğretmen, Bayburt/Merkez.

Kaynak Kişi 6: Mehmet Türk,75 yaşında, ortaokul mezunu, emekli, Bayburt/ Gez Köyü.

Kaynak Kişi 7: Hanefi Kırtan, 60 yaşında, lise mezunu, terzi, Bayburt/Merkez. 